\title{
Volitional Swimming Kinematics of Blacktip Sharks, Carcharhinus limbatus, in the Wild
}

\author{
Marianne E. Porter*(D), Braden T. Ruddy (D) and Stephen M. Kajiura \\ Department of Biological Sciences, Florida Atlantic University, Boca Raton, FL 33433, USA; \\ bruddy2018@fau.edu (B.T.R.); kajiura@fau.edu (S.M.K.) \\ * Correspondence: me.porter@fau.edu; Tel.: +1-561-297-1288 \\ Received: 30 September 2020; Accepted: 15 December 2020; Published: 18 December 2020
}

\begin{abstract}
Recent work showed that two species of hammerhead sharks operated as a double oscillating system, where frequency and amplitude differed in the anterior and posterior parts of the body. We hypothesized that a double oscillating system would be present in a large, volitionally swimming, conventionally shaped carcharhinid shark. Swimming kinematics analyses provide quantification to mechanistically examine swimming within and among species. Here, we quantify blacktip shark (Carcharhinus limbatus) volitional swimming kinematics under natural conditions to assess variation between anterior and posterior body regions and demonstrate the presence of a double oscillating system. We captured footage of 80 individual blacktips swimming in the wild using a DJI Phantom 4 Pro aerial drone. The widespread accessibility of aerial drone technology has allowed for greater observation of wild marine megafauna. We used Loggerpro motion tracking software to track five anatomical landmarks frame by frame to calculate tailbeat frequency, tailbeat amplitude, speed, and anterior/posterior variables: amplitude and frequency of the head and tail, and the body curvature measured as anterior and posterior flexion. We found significant increases in tailbeat frequency and amplitude with increasing swimming speed. Tailbeat frequency decreased and tailbeat amplitude increased as posterior flexion amplitude increased. We found significant differences between anterior and posterior amplitudes and frequencies, suggesting a double oscillating modality of wave propagation. These data support previous work that hypothesized the importance of a double oscillating system for increased sensory perception. These methods demonstrate the utility of quantifying swimming kinematics of wild animals through direct observation, with the potential to apply a biomechanical perspective to movement ecology paradigms.
\end{abstract}

Keywords: aerial drone; body curvature; Carcharhinidae; elasmobranch; flexion; tail beat frequency

\section{Introduction}

The undulatory wave used for swimming can vary an individual fish, among species, and with postural reconfiguration [1-5]. Head yaw has been observed in both hammerhead (Sphyrnidae) and more conventionally shaped (Carcharhinidae) shark species [6-8]. Head yaw can be decoupled from tail beat frequency, which suggests that more than one wavelength may be generated during swimming. This is known as a double oscillating system, where the undulatory wave in the anterior body differs from the posterior body, and has been identified in sturgeon, eels, and lamprey [1-3]. In two hammerhead species, recent work showed a double oscillating system where wave frequency was greater, and amplitude was smaller in the anterior body compared to the posterior body [9]. Swimming kinematics can vary by habitat and experimental conditions; for example, sharks swimming in a flume expended more energy, and tailbeat amplitude decreased relative to speed, when compared to sharks swimming in a semi-natural pond [10]. Here, we utilize an aerial drone to quantify swimming kinematics of a coastal shark species to determine if sharks employ a double oscillating system under 
natural conditions. Utilizing aerial drones to record volitionally swimming animals in the wild provides an opportunity to gather data on large adult specimens that are not able to be maintained in captivity, or that might exhibit compromised swimming performance due to the constraints of the tank.

Until recently, aerial based studies were necessarily conducted with manned aircraft, which are expensive to operate, require specialized training, and are large and loud and, hence, disruptive [11-13]. The recent advent of Unmanned Aircraft Systems (UAS) technology has provided researchers with the ability to inexpensively and less obtrusively observe animals in their natural habitat [14-19]. UAS platforms (drones) are relatively easy to fly compared to manned aircraft, making them accessible to a wide range of researchers, and are portable, enabling them to be operated from remote locations where aircraft would be impractical. The accessibility of GPS positioning allows the drone to hover over a target of interest, which permits data collection that would have been previously impossible without the use of a helicopter equipped with a gyroscopically stabilized camera system. Similarly, the ability to record with a camera aimed directly downward while hovering allows for footage to be collected in a plane orthogonal to the camera, permitting distortion-free measurement. Therefore, the development of UAS platforms, coupled with the miniaturization of gimbal stabilization, high quality digital recording, and geo-referenced imaging, all combine to provide researchers with high resolution images of exceptional quality.

The imaging capabilities on UAS, ROV (remotely operated vehicle), and AUV (autonomous underwater vehicle) platforms allow researchers to discretely record photos and videos from animals exhibiting natural behaviors, and this is becoming more prevalent in studies of marine megafauna [2031]. The utilization of aerial drones for elasmobranch research is an emergent technique that has provided a new tool for scientists to explore the life history and behaviors of various species. UAS platforms have been employed in elasmobranch research to quantify elements used in movement ecology paradigms such as: species density, habitat utilization, social and foraging behaviors, and fine scale movement patterns $[17,18,24,32-39]$. Here, we describe UAS applications on a smaller spatiotemporal scale to quantify biomechanical swimming kinematics.

We used aerial drones to capture footage from adult blacktip sharks (C. limbatus) in the wild and analyze volitional swimming kinematics using a workflow previously described for animals in a captive study [9]. We aim to quantify volitional swimming speed in relation to tailbeat frequency, tail peak-peak amplitude, and body curvature. We quantify regional body amplitude and frequency and body curvature (flexion frequency and amplitude), to identify variations between the anterior and posterior body. Based on previous research, we hypothesized that double oscillating systems will be seen in conventionally shaped sharks (carcharhinids) swimming under natural conditions [1-10]. Furthermore, this study demonstrates the feasibility of using aerial drones to collect kinematic data from sharks in the wild at the smallest scales described in movement ecology paradigms.

\section{Materials and Methods}

\subsection{Video Collection}

We used a commercially available unmanned aerial vehicle, the DJI Phantom 4 Pro aerial drone (Shenzhen Dajiang Baiwang Technology Co., Ltd., Shenzhen, China), to film blacktip sharks (C. limbatus) volitionally swimming in the wild in the nearshore waters of Singer Island, Florida, USA (Figure 1). This location in the Western Atlantic is known from prior aerial surveys to have high aggregational abundance of blacktip sharks during the winter months (January-March) [40]. The generally clear water offers good visibility, and the seafloor is mostly lightly colored sand. The combination of clear water and a light-colored seafloor provides optimum conditions for visualizing animals from the air [33]. We did not quantify visibility or depth from the footage, but the depth was sufficiently shallow and the water sufficiently clear to enable us to visualize sand ripples on the seafloor and easily distinguish anatomical landmarks on the sharks. In addition, the sharks are typically found close 
to the beach where the nearby sand dunes provide a wind break that minimizes surface ripples and allows the surface of the water to be relatively distortion-free.
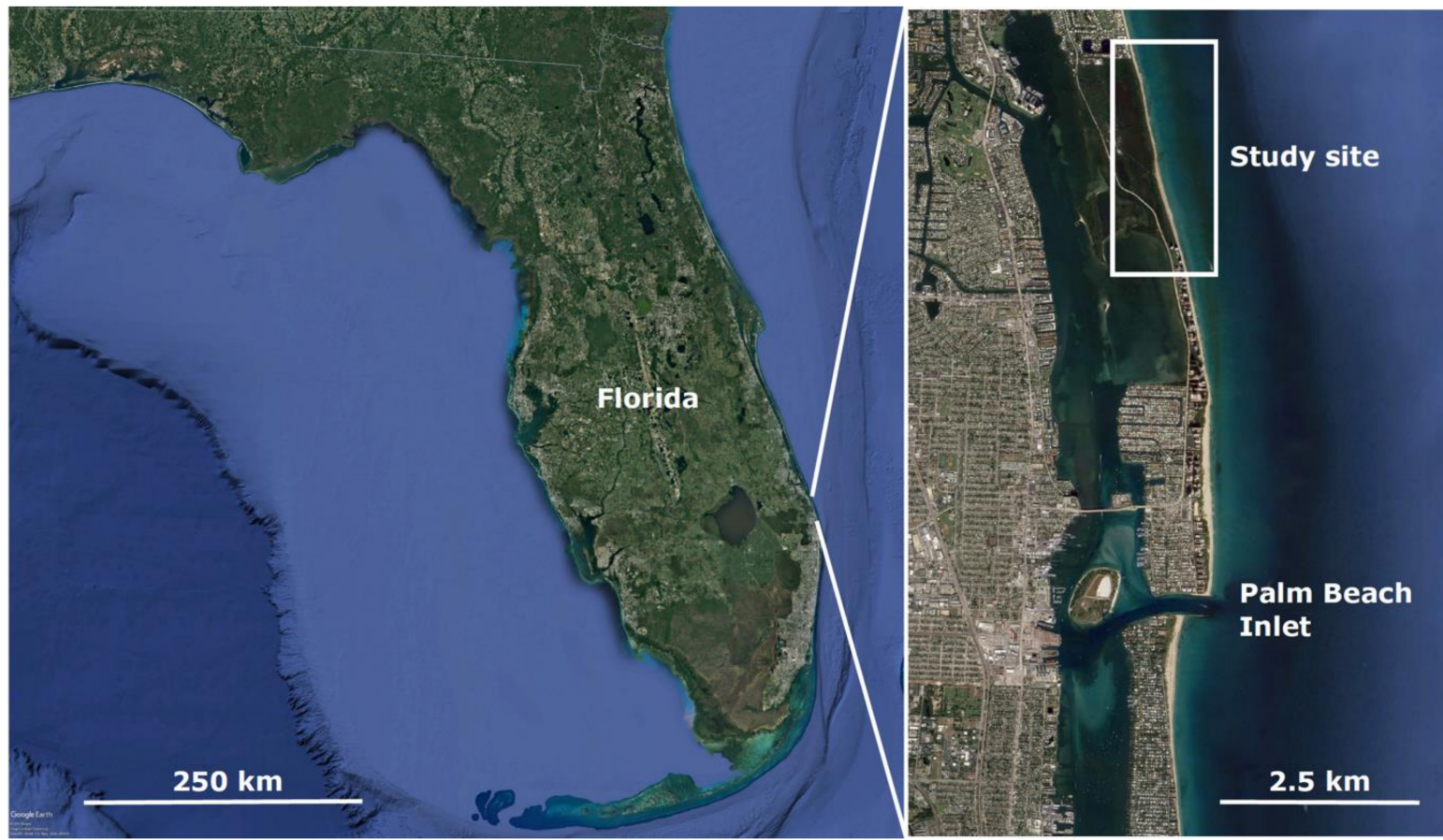

Figure 1. The survey area is in the Western Atlantic Ocean near Palm Beach County, Florida (USA). Flights took place offshore of John D. MacArthur State Park on Singer Island, FL, USA, north of the Palm Beach Inlet.

We flew the drone between January and April of 2018, and flights originated either from the shoreline or a $7.5 \mathrm{~m}$ vessel less than $100 \mathrm{~m}$ from shore. On average, wind speed during drone flights was $8.2 \pm 1.3 \mathrm{~km} / \mathrm{h}$, ocean swells were $0.64 \pm 0.21 \mathrm{~m}$, and flights took place from 07:00-10:00 local time. The time of year was selected to capitalize on seasonal shark aggregations in this area during the winter months [40]. A previous study outlined the challenges that arise from using aerial drones for field work. These include the angle of the sun which can produce significant glare off the surface of the water during mid-day [41]. Flights took place early in the morning while the sun was low on the horizon, which minimized surface glare. From the point of take-off, we would fly the drone approximately 400 $\mathrm{m}$ north at an altitude of $50 \mathrm{~m}$. By only flying from south to north, and only filming sharks swimming from north to south, we ensured that every shark filmed had not been previously recorded that day.

When sharks were spotted, the drone would descend to an altitude of $25 \mathrm{~m}$ and hover over the sharks. Altitudes of $25 \mathrm{~m}$ were chosen to ensure that we could visualize all the anatomical landmarks for kinematic analyses. Hovering accuracy of the Phantom 4 Pro is $0.1 \mathrm{~m}$ vertical and $0.3 \mathrm{~m}$ horizontal, suggesting minimal deviation from the stationary hovering position. Hovering continued until the sharks had completely passed through the camera's field of view. The drone would then ascend to an altitude of $50 \mathrm{~m}$ and flight would continue north looking for additional sharks. Flights were constrained by drone battery life, and we would cease surveys when battery life reached $10 \%$ charge. On average flights lasted $25 \mathrm{~min}$. Footage was captured with the drone's onboard gimbal-stabilized camera oriented orthogonal to the water surface. All footage was recorded at a resolution of $3840 \times$ 2160 pixels and $60 \mathrm{fps}$.

A total of 112 survey flights across 28 days were completed over four months, which produced $56 \mathrm{~h}$ of video. From the video we identified events where individual sharks would swim, for at least three tailbeat cycles, across the camera's field of view from north to south (Video S1). Sharks were examined only if they were near the surface and all anatomical landmarks were clearly visible. Using 
these criteria, we used iMovie 10.1.14 (Apple Inc., Cupertino, CA, USA) to trim the footage down to 80 individual video clips. All measurements were standardized to the body length (bl) of each shark to compensate for size variation among individuals. A previous study used a similar standardized measurement to mitigate for variations in apparent size due to swimming depth and to adjust for size differences between adults and juveniles [9]. Swimming depth and ontogenetic stages remain uncontrolled variables in this study; however, tagging work on this population has found that the blacktip sharks average $171.75+7.86 \mathrm{~cm}$ total length (Kajiura, unpublished data). While there is a possibility that the same individual was filmed on different days, the probability is low given the large aggregation sizes and densities [40].

\subsection{Kinematic Analysis}

We used Loggerpro 3.10.1 (Vernier Software \& Technology, Beaverton, OR, USA) to track the movement of the blacktip sharks in each video clip. Five anatomical landmarks along the body midline were selected for analysis: (A) tip of the rostrum, (B) origin of the first dorsal fin, (C) insertion of the first dorsal fin, (D) caudal peduncle, and (E) tip of the caudal fin dorsal lobe (Figure 2). We used Loggerpro to digitize the location of each of the five points on a shark for every frame of video over three complete tailbeat cycles. The Loggerpro software produced positional data ( $X, Y$ coordinates) for each point tracked in a video clip. We standardized all measurements to animal body length (total length from tip of rostrum to tip of the caudal fin dorsal lobe) to account for variations in depth and size in free swimming sharks [9].
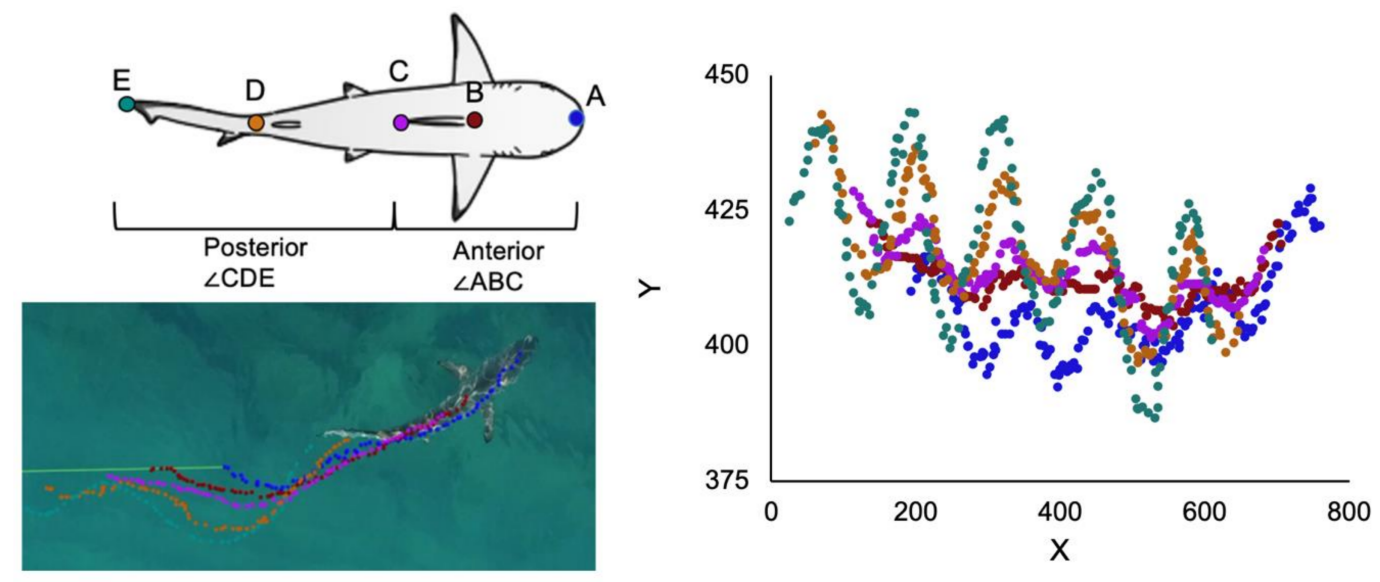

Figure 2. Blacktip sharks swimming in the wild were filmed with an aerial drone. Point tracking software was used to follow five anatomical landmarks (A-E) along the body midline through three tailbeat cycles. These positional data were then used to calculate kinematics variables. The green line (lower left panel) sets the scale for the shark body length (bl).

Swimming speed $(V)$ was quantified as the displacement of the dorsal fin insertion (Figure 2; point $B$ ) from frame to frame over time between frames and was expressed as body lengths per second $(\mathrm{bl} / \mathrm{s})$. Environmental factors, such as turbulence and current, might have contributed to the calculated swimming speed. Tailbeat frequency $(F)$ was defined as the time required for the tip of the upper lobe of the caudal fin (Figure 2; point E) to complete one full lateral excursion from one side of the body to the other and return to the starting position. Tailbeat frequency was expressed in Hertz $(\mathrm{Hz})$. Stride length was quantified as swimming speed $(V ; \mathrm{bl} / \mathrm{s})$ over tailbeat frequency $(F ; \mathrm{Hz})$ where $V / F$ was measured in body length (bl). Tailbeat amplitude $(A)$ was defined as the peak-to-peak distance between lateral excursions of the tip of the upper lobe of the caudal fin (Figure 2; point E) and was expressed as a proportion of body length (bl). Amplitude and swimming speed were standardized by body length, to remove effects of size among individuals. Strouhal number (St) was used to quantify swimming efficiency and was calculated as: $S t=A F / V$ [42]. Additionally, we quantified slippage ratio, 
another metric for swimming efficiency, defined as $V / v$ where $V$ is the animal's swimming speed (bl/s) and $v$ is the speed of the body's propulsive wave $(\mathrm{bl} / \mathrm{s})$. Wave speed $(v)$ was calculated as the vectored quantity from the volitional speed of the animal and lateral speed of the tail, which was $0.5 F^{*} A$.

To examine the body as a double oscillating system, we quantified amplitudes and frequencies of points $\mathrm{A}$ and $\mathrm{E}$ in the anterior and posterior body, respectively (Figure 2). Anterior amplitude and frequency (Point A) will be referred to as head yaw and head yaw frequency [43]. Posterior amplitude and frequency (Point E) are synonymous with tailbeat frequency and tailbeat peak-peak amplitude as described above.

Previous research on other shark species quantified regional body curvature by examining anterior body flexion amplitude and frequency [9]. To determine if this was also found in blacktip sharks swimming in the wild, we calculated flexion amplitude $\left(^{\circ}\right)$ and flexion frequency $(\mathrm{Hz})$ for the anterior and posterior regions. Flexion amplitude $\left(^{\circ}\right)$ was calculated as the maximum angular displacement from the midline for both the anterior (points $A, B, C$ ) and posterior (points C, D, E) body regions (Figure 2) [9]. Flexion frequency (Hz) was calculated as the maximum displacement per time averaged over three complete tailbeats.

To understand the phase relationship between the anterior and posterior regions, the positional offset of anterior and posterior waves was quantified as $O=(A \lambda / 2)-(P \lambda / 2)$. Where $A \lambda$ is the anterior wavelength (bl) calculated as anterior $v(\mathrm{bl} / \mathrm{s}) /$ head yaw frequency $(\mathrm{Hz})$, and $P \lambda$ is the posterior wavelength (bl) calculated as posterior $v(\mathrm{bl} / \mathrm{s}) /$ tailbeat frequency $(\mathrm{Hz})$.

\subsection{Statistical Analyses}

We utilized nonparametric statistics on untransformed data since they did not pass assumptions of normality and homoscedasticity required for parametric statistics. We used generalized linear models to determine differences in whole body swimming kinematics. Tailbeat frequency $(\mathrm{Hz})$, tail peak-peak amplitude (bl), and posterior flexion amplitude $\left({ }^{\circ}\right.$ ) were used as main effects to understand swimming speed (bl/s) in wild blacktip sharks. We used a generalized linear model to examine the effects of tailbeat frequency and tail peak-peak amplitude on body curvature (posterior flexion amplitude). We examined regional variation (anterior and posterior) for head yaw amplitude and frequency compared to tailbeat amplitude and frequency using Wilcoxon rank sum tests. Finally, we examined regional differences in body curvature using anterior and posterior flexion frequency and amplitude using Wilcoxon rank sum tests. All statistical analyses were completed using JMP 14.3.0 (SAS Institute Inc., Cary, NC, USA).

\section{Results}

The mean (plus standard deviation) swimming speed of blacktip sharks in the wild was $0.75 \pm$ $0.18 \mathrm{bl} / \mathrm{s}$, their tailbeat frequency was $0.82 \pm 0.24 \mathrm{~Hz}$, stride length was $0.98 \pm 0.30 \mathrm{bl}$, and their tail peak-peak amplitude was $0.24 \pm 0.08$ bl. Blacktip swimming efficiency, as measure by Strouhal number, was $0.25 \pm 0.01$ and the slippage ratio was $0.99 \pm 0.001$.

\subsection{Whole Body Kinematics}

Using generalized linear models, we found a significant relationship between swimming speed $(\mathrm{bl} / \mathrm{s})$ and kinematic variables (Chisq $=104.25 ; \mathrm{DF}=3 ; p<0.001)$. Both tailbeat frequency $(\mathrm{Hz})$ and tail peak-peak amplitude (bl) were significant effects (Chisq $=74.82$ and 87.66, respectively; $p<0.001$ ). Posterior flexion amplitude was not a significant effect when examining swimming speed (bl/s). As speed increases during volitional straight swimming, both tailbeat frequency $\left(R^{2}=0.157\right)$ and tail peak-peak amplitude increase $\left(R^{2}=0.059\right.$; Figure 3$)$. 

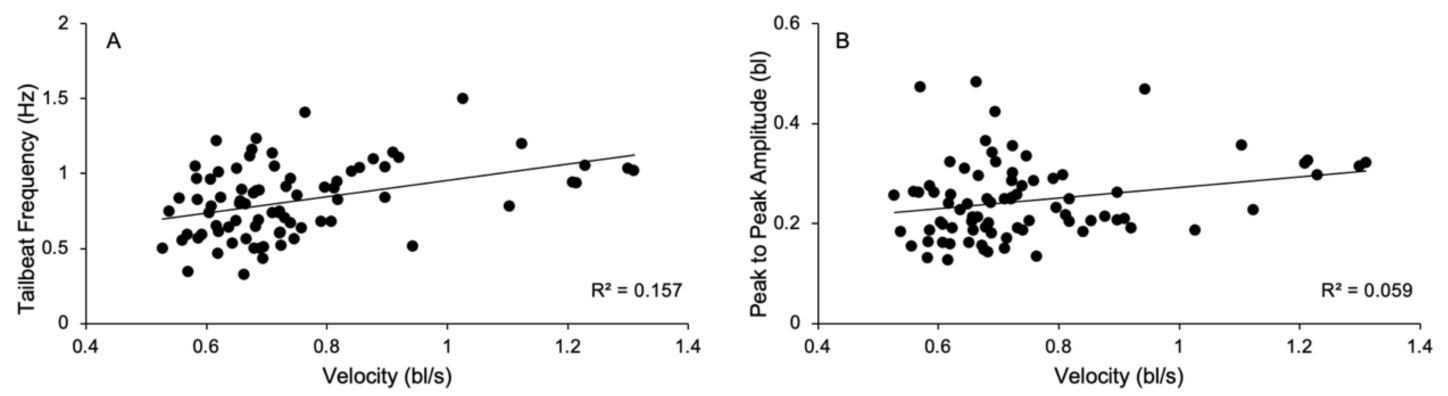

Figure 3. Both tailbeat frequency (left) and tail peak-peak amplitude (right) increase significantly over a range of speeds observed in wild swimming blacktip sharks. The $\mathrm{R}^{2}$ values illustrate low predictability, but these data represent volitional swimming and likely do not reflect the range of swimming speeds of which this species is capable.

\subsection{Body Curvature}

We used generalized linear models to examine the relationships between body curvature (posterior flexion amplitude) and kinematic variables: tailbeat frequency $(\mathrm{Hz})$, and tail peak-peak amplitude (bl; Figure 4). The generalized linear model was significant (Chisq $=80.86$; $\mathrm{DF}=2 ; p<0.001$ ), and tailbeat frequency and tail peak-peak amplitude were both significant effects (Chisq $=29.77$ and $p<0.001$; Chisq $=7.49$ and $p=0.006$; Figure 4$)$. As posterior flexion increases, tailbeat frequency decreases $\left(R^{2}=\right.$ $0.6)$ and tail peak-peak amplitude increases $\left(R^{2}=0.472\right)$.
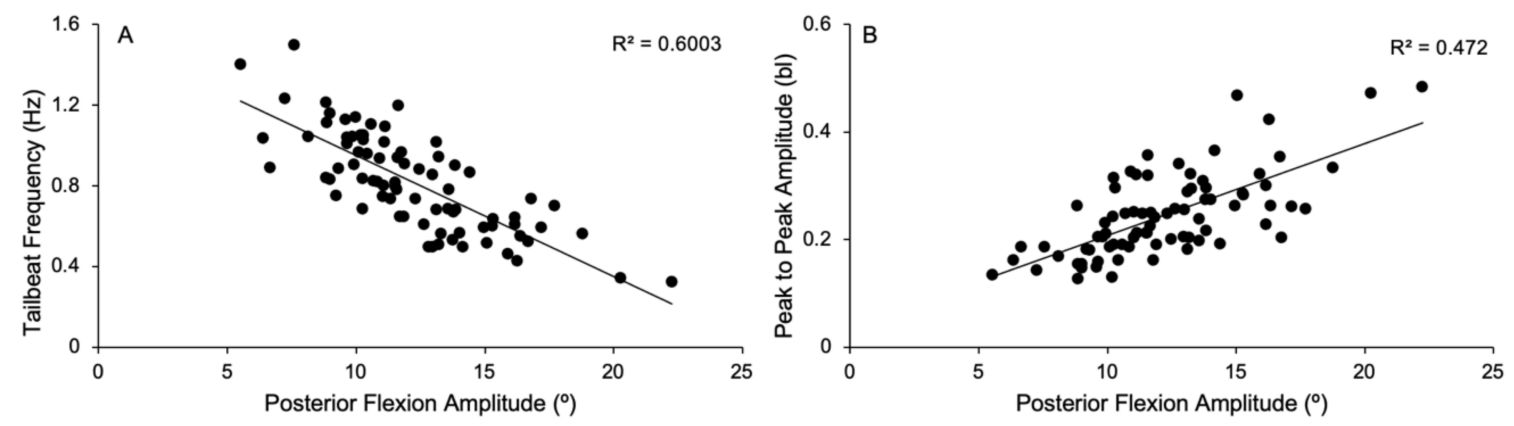

Figure 4. As posterior flexion amplitude increases, tailbeat frequency (left) significantly decreases while tail peak-peak amplitude (right) increases. These data show the relationships between two common swimming kinematics variables (tailbeat frequency and amplitude) with body curvature, specifically in the posterior body.

\subsection{Body Region}

We examined the kinematic variation between anterior and posterior body movements during blacktip shark volitional swimming (Figure 5). Using a Wilcoxon rank sum test, we found that peak-peak amplitude was nearly two times greater in the posterior region $(0.26 \pm 0.08)$ compared to the anterior region $(0.13 \pm 0.03 ; Z=9.80 ; p<0.001$; Figure $5 \mathrm{~A})$. The frequency of head yaw (Point $\mathrm{A}$; $1.23 \pm 0.37 \mathrm{~Hz}$ ) is significantly greater than the frequency of the tailbeat (Point E; $0.82 \pm 0.24 \mathrm{~Hz} ; \mathrm{Z}$ $=-6.96 ; p<0.001$; Figure $5 \mathrm{~B}$ ). We calculated the phase relationship as the positional offset between the anterior and posterior wave forms (Point $\mathrm{A}$ and $\mathrm{E}$ ) and found that, on average, the offset between wave peaks was $0.20 \mathrm{bl} \pm 0.15 \mathrm{bl}$. 

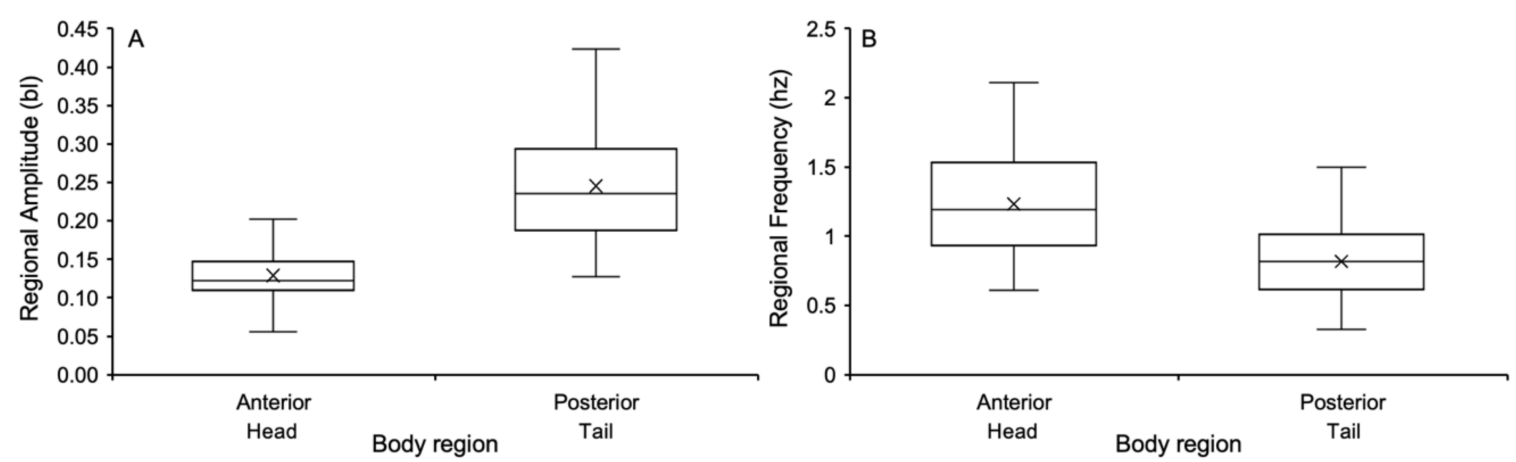

Figure 5. The anterior and posterior region of volitionally swimming blacktips are decoupled. Regional amplitude is greater at the tail whereas regional frequency is greater at the head. In each box and whisker plot, the " $X$ " is the mean, the "line" is the median, the "box" represents the 75th and 25th percentiles, and the "whiskers" are the standard deviation.

Using a Wilcoxon rank sum test to assess body curvature among regions, we found that flexion $\left(^{\circ}\right)$ was $33 \%$ greater in the posterior $(12.21 \pm 3.13)$ compared to the anterior region flexion $(8.28 \pm 1.74 ; \mathrm{Z}=$ 8.17834; $p<0.001 ;$ Figure $6 \mathrm{~A}$ ). Body flexion frequency was significantly greater in the anterior region $(1.35 \pm 0.33 \mathrm{~Hz})$ compared to the posterior region $(0.90 \pm 0.24 \mathrm{~Hz} ; \mathrm{Z}=-8.513 ; p<0.001$; Figure $6 \mathrm{~B})$.
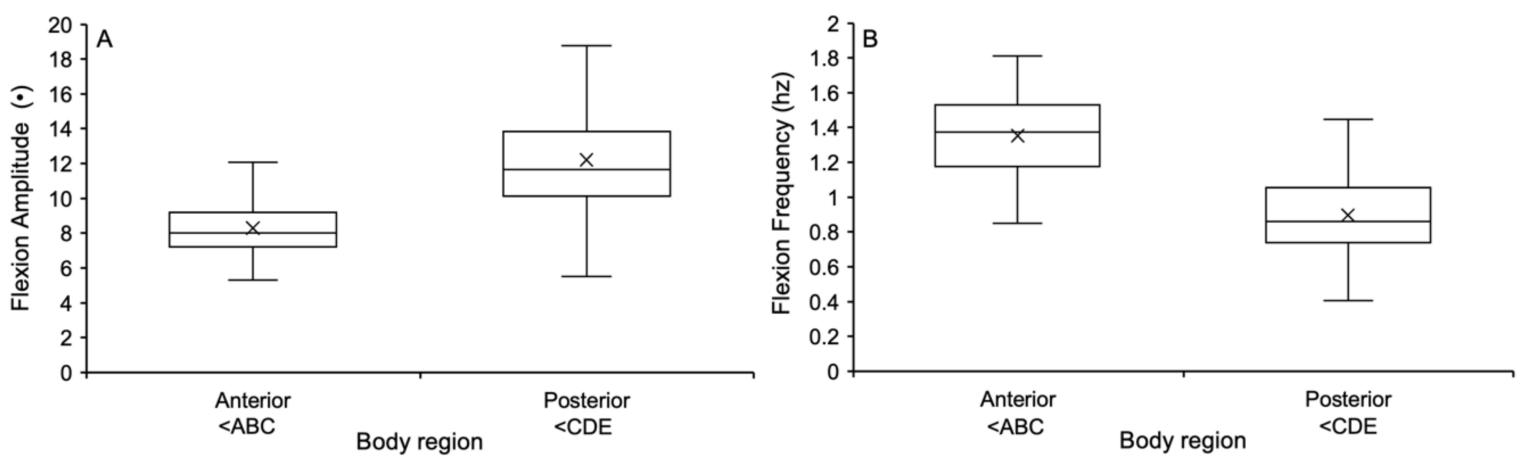

Figure 6. Body curvature varies significantly between the anterior and posterior portions of the body. Flexion amplitude is significantly greater in the posterior region while flexion frequency is significantly greater in the anterior region. In each box and whisker plot, the " $\mathrm{X}$ " is the mean, the "line" is the median, the "box" represents the 75th and 25th percentiles, and the "whiskers" are the standard deviation.

\section{Discussion}

We utilized an aerial drone to collect fine-scale kinematic data on blacktip sharks volitionally swimming in the wild, and we demonstrate that under certain environmental conditions, even large sharks are amenable to the type of biomechanics studies previously restricted to species or life history stages small enough to be housed in a laboratory or aquarium setting. We found that tailbeat frequency and amplitude significantly impact swimming speed, while increases in body curvature occur with decreases in tailbeat frequency and increases in amplitude (Figure 3). We examined regional amplitude and frequency and found that tip of the snout (Point A) exhibited a greater frequency compared to the tail (Point E), while the tail had greater amplitude (Figure 5). Body curvature also varied regionally, where flexion amplitude was greater in the posterior region of the body while flexion frequency was greater in the anterior region (Figure 6). Further, we demonstrate that a workflow to analyze volitional swimming kinematics in a lab can be adapted to quantify the swimming kinematics of adult blacktip sharks swimming in the wild (Figures 2-5) [9].

Electronic tags and animal-borne biologgers have been previously used to record swimming kinematic variables. These instruments have derived either direct measurements of tail beat frequency [44] or indirect measures via interpretation of acceleration data [45]. Electronic tags 
can remain on the animal for an extended duration and can collect a substantial quantity of data. However, they require each individual to be captured and instrumented, which limits the number of individuals that can be sampled, and there can be physiological costs to the animal as well $[25,38]$. Currently, the monetary cost associated with electronic tags is also significant, in the range of thousands of US dollars, as well as the time and effort required to capture and instrument each individual, then recover the tags afterwards. In contrast, aerial drones can sample many individuals with minimal effort, cost, and time [24-28,37]. Analyzing video footage of swimming animals provides a direct measurement of kinematic variables compared to interpretating acceleration data. Finally, this technique permits collection of other variables, such as body curvature, that are not able to be recorded with biologgers. For example, we were able to track five points per animal in this study, whereas biologgers would record measurements from only one point on the animal. This framework using drones is more effective for describing fine scale kinematics (body curvature and maneuvering) while biologgers, which can collect data over the course of days, weeks, or longer, are better for understanding larger scale movements.

Previous research synthesizing swimming efficiency, as measured by Strouhal numbers (St), has found that swimming animals will operate between $0.2-0.4 S t$, where optimal thrust is generated [42, 46-52]. The blacktip sharks in this study had mean St of 0.25 , which places them within this range for optimal and efficient swimming. The mean speed for blacktips in the wild was $0.75 \mathrm{bl} / \mathrm{s}$ (range $0.33-1.5$ $\mathrm{bl} / \mathrm{s}$ ) and this falls within the range $(0.25-1.2 \mathrm{bl} / \mathrm{s})$ of sharks in captive (flume, semi-natural lagoons, and tank) studies $[9,10,53,54]$. The data presented in this study are from volitional swimming and represent only a small range of speeds of which blacktip sharks are capable. Recording individuals in their natural habitat also allows quantification of swimming kinematics during schooling, and during predator/prey interactions; neither of which are possible in a captive setting [55]. Mean tailbeat frequency $(\mathrm{Hz})$ of blacktip sharks swimming in the wild was $0.82 \mathrm{~Hz}$, also within the range of values obtained from tagged animals swimming $(0.15-1.16 \mathrm{~Hz})$ in the wild [56-58]. Lastly, mean peak-peak amplitude was $0.24 \mathrm{bl}$, which approaches the calculated optimal amplitude of $20 \%$ of bl [46].

Tailbeat frequency and amplitude both increased with increasing swimming speed (bl/s) (Figure 3). A positive correlation between tail beat frequency and swimming speed was also found in several species of volitionally swimming sharks in an aquarium, including two other carcharhinid species, the bull shark, Carcharhinus leucas, and the reef blacktip, C. melanopterus [54]. However, that study found an inverse correlation between tail beat amplitude and swimming speed, which differed from the positive correlation in the present study (Figure 3). These kinematic differences might result from the constraints of their tank environment, or species level morphological and/or mechanical differences. For example, caudal, dorsal, and pectoral fins vary by species and can impact swimming kinematics. The bodies of sharks have been shown to operate as springs or brakes depending on the loading [59-64]. The mean swimming speed of bull sharks (C. leucas) is $0.58 \mathrm{bl} / \mathrm{s}$ and their tailbeat frequency is 0.78 $\mathrm{Hz}$, whereas reef blacktip sharks (C. melanopterus) swim faster at $0.80 \mathrm{bl} / \mathrm{s}$ using a $1.13 \mathrm{~Hz}$ tailbeat [54]. Similarly, the scalloped hammerhead shark (Sphyrna lewini) swam on average $0.73 \mathrm{bl} / \mathrm{s}$ with a $1.3 \mathrm{~Hz}$ tailbeat and the bonnethead shark (Sphyrna tiburo) swam $0.62 \mathrm{bl} / \mathrm{s}$ with a $1.05 \mathrm{~Hz}$ tailbeat [9]. The mean swimming speed $(0.75 \mathrm{bl} / \mathrm{s})$ and tailbeat frequency $(0.82 \mathrm{~Hz})$ for blacktip sharks (C. limbatus) swimming in the wild in the present study are within those ranges. Future work should examine a larger range of swimming speeds and behaviors.

We found that body curvature, as measured by posterior flexion $\left({ }^{\circ}\right)$, did not vary with swimming speed in these blacktip sharks swimming in the wild. Posterior flexion increased with tail peak-peak amplitude but decreased with tailbeat frequency (Figure 4). Previous research showed that flexion of the body midline, similar to flexion measured here, was a strong predictor of turning performance [65]. Capturing body curvature modulations is important to understand the traveling wave down the bodies of large fishes. Future studies could use these methods to quantify straight swimming, turning or maneuvering using an aerial drone $[33,65,66]$. 
Previous research on two species of hammerhead shark, the scalloped hammerhead (S. lewini) and the bonnethead (S. tiburo), found that both hammerhead species exhibited a greater flexion frequency anteriorly and larger flexion amplitudes posteriorly, which the authors called a double oscillating system [9]. They proposed that this was specific to cartilaginous fishes and used to increase sensory perception [1-3,9]. In this study, we also found that kinematic variables differed between the anterior and posterior body regions (Figures 5 and 6 ). The head (Point A) and the body curvature measured by anterior flexion had a greater frequency while the tail (Point E) and body curvature measured as posterior flexion had greater amplitudes. In addition, the offset between the wave produced by the head (Point A) and the tail (Point E) was $0.20 \pm 0.15 \mathrm{bl}$. This offset and rather large standard deviation suggest that these points are sometimes in phase and sometimes out of phase, which is expected in an asynchronous system. Together, these findings suggest that blacktip sharks may also be operating as a double oscillating system as previously described in hammerhead species. The double oscillating system results presented here on blacktip sharks swimming in the wild contribute to the growing body of literature on variable undulatory wave propagation in cartilaginous fishes and suggests that this mode of swimming may be useful for increasing sensory perception.

This study was possible because the blacktip sharks occurred in shallow water over a light, sandy seafloor. The clear water and light-colored seafloor facilitated visualization of the sharks and allowed the anatomical landmarks to be easily distinguished. Sharks found in more turbid environments, or occurring over dark, complex backgrounds, would be more difficult to successfully image. Similarly, if the sharks were located deeper in the water column, distortion from the water's surface would prevent clear visualization of the animals and make this project less feasible. More challenging conditions may be an opportunity for other technologies such as ROVs and AUVs to film animals swimming either above or below the platform [29-31]. The specific requirements of clear water, and a relatively distortion-free surface, limit the utility of this technique, however this fine scale data collection may be possible in other study systems where aerial surveys and drone technology are being utilized and can allow for studying animals with a lens toward biomechanics within movement ecology paradigms $[17,18,32,38,39,67]$.

\section{Conclusions}

This study modifies a workflow developed for laboratory studies by using direct observations from aerial drone video to quantify swimming kinematics in the wild, thus enabling researchers to examine movement ecology from a biomechanical perspective $[3,9,32]$. We found that tailbeat frequency and amplitude increased significantly with increasing speed. Tailbeat frequency decreases and tail peak-peak amplitude increases as posterior body flexion angle increases. Anterior and posterior regional variables were significantly different, supporting our hypothesis that we would find a double oscillating system in cartilaginous fishes swimming in natural environments and add to the growing literature on variable wave propagation. We found that the frequency of head movements and body flexion in the anterior body region was greater than the posterior regions, which has been hypothesized to enhance sensory perception in these species. The amplitude of the tail and amplitude of flexion at the tail were greater when compared to the anterior regions, which may have implications for thrust production. These methods can be employed in studies using aerial footage to provide a biomechanical application toward animal movements in the wild.

Supplementary Materials: Video S1 is available online at https://osf.io/kxfnp/.

Author Contributions: Conceptualization, M.E.P. and S.M.K.; methodology, M.E.P., B.T.R. and S.M.K.; validation, B.T.R. and M.E.P.; formal analysis, B.T.R. and M.E.P.; resources, S.M.K. and M.E.P.; data curation, B.T.R. and M.E.P.; writing-Original draft preparation, M.E.P., B.T.R. and S.M.K.; writing-Review and editing, M.E.P., B.T.R. and S.M.K.; supervision, M.E.P.; project administration, M.E.P.; funding acquisition, M.E.P., B.T.R. and S.M.K. All authors have read and agreed to the published version of the manuscript.

Funding: This work was funded in part by the National Science Foundation (IOS-1941713) to M.E.P., the Colgan Foundation to S.M.K., and the Save our Seas Foundation to M.E.P. and S.M.K. This work was supported by the Society for Integrative and Comparative Biology Grant in Aid of Research to B.T.R. 
Acknowledgments: We thank Laura Lindsey for aiding with digitization. We also thank the FAU Elasmolab volunteers for helping to deploy and catch the drone on the boat. Three anonymous reviewers provided comments that improved this manuscript.

Conflicts of Interest: The authors declare no conflict of interest.

\section{References}

1. Long, J.; John, H.; Porter, M.E.; Root, R.G.; Liew, C.W. Go Reconfigure: How Fish Change Shape as They Swim and Evolve. Integr. Comp. Biol. 2010, 50, 1120-1139. [CrossRef]

2. Long, J.H. Morphology, mechanics, and locomotion: The relation between the notochord and swimming motions in sturgeon. Environ. Biol. Fishes 1995, 44, 199-211. [CrossRef]

3. Root, R.G.; Courtland, H.-W.; Pell, C.A.; Hobson, B.; Twohig, E.J.; Suter, R.B.; Iii, W.R.S.; Boetticher, N.C.; Long, J.H. Swimming fish and fish-like models: The harmonic structure of undulatory waves suggests that fish actively tune their bodies. In Proceedings of the 11th International Symposium on Unmanned Untethered Submersible Technology (UUST), Autonomous Undersea Systems Institute, Lee, NH, USA, 23-25 August 1999; Volume 11, pp. 378-388.

4. Long, J.H.; Adcock, B.; Root, R.G. Force transmission via axial tendons in undulating fish: A dynamic analysis. Comp. Biochem. Physiol. A Mol. Integr. Physiol. 2002, 133, 911-929. [CrossRef]

5. Porter, M.E.; Roque, C.M.; Long, J.H., Jr. Turning maneuvers in sharks: Predicting body curvature from axial morphology. J. Morphol. 2009, 270, 954-965. [CrossRef]

6. Kajiura, S.M.; Holland, K.N. Electroreception in juvenile scalloped hammerhead and sandbar sharks. J. Exp. Biol. 2002, 205, 3609. [CrossRef]

7. Kajiura, S.M.; Forni, J.B.; Summers, A.P. Maneuvering in juvenile carcharhinid and sphyrnid sharks: The role of the hammerhead shark cephalofoil. Zoology 2003, 106, 19-28. [CrossRef]

8. Kajiura, S.M. Electroreception in neonatal bonnethead sharks, Sphyrna tiburo. Mar. Biol. 2003, 143, $603-611$. [CrossRef]

9. Hoffmann, S.L.; Warren, S.M.; Porter, M.E. Regional variation in undulatory kinematics of two hammerhead species: The bonnethead (Sphyrna tiburo) and the scalloped hammerhead (Sphyrna lewini). J. Exp. Biol. 2017, 220, 3336-3343. [CrossRef]

10. Lowe, C. Kinematics and critical swimming speed of juvenile scalloped hammerhead sharks. J. Exp. Biol. 1996, 199, 2605-2610.

11. Watts, A.C.; Perry, J.H.; Smith, S.E.; Burgess, M.A.; Wilkinson, B.E.; Szantoi, Z.; Ifju, P.G.; Percival, H.F. Small unmanned aircraft systems for low-altitude aerial surveys. J. Wildl. Manag. 2010, 74, 1614-1619. [CrossRef]

12. Bouché, P.; Lejeune, P.; Vermeulen, C. How to count elephants in West African savannahs? Synthesis and comparison of main gamecount methods. Biotechnol. Agron. Soc. Environ. 2012, 16, 77-91.

13. Dunham, K.M. Trends in populations of elephant and other large herbivores in Gonarezhou National Park, Zimbabwe, as revealed by sample aerial surveys. Afr. J. Ecol. 2012, 50, 476-488. [CrossRef]

14. Watts, A.; Ambrosia, V.; Hinkley, E. Unmanned aircraft systems in remote sensing and scientific research: Classification and considerations of use. Remote Sens. 2012, 4, 1671-1692. [CrossRef]

15. Erbe, C.; Parsons, M.; Duncan, A.; Osterrieder, S.K.; Allen, K. Aerial and underwater sound of unmanned aerial vehicles (UAV). J. Unmanned Veh. Syst. 2017, 5, 92-101. [CrossRef]

16. Christiansen, F.; Rojano-Doñate, L.; Madsen, P.T.; Bejder, L. Noise levels of multi-rotor unmanned aerial vehicles with implications for potential underwater impacts on marine mammals. Front. Mar. Sci. 2016, 3, 277. [CrossRef]

17. Kiszka, J.J.; Heithaus, M.R. Using Aerial Surveys to Investigate the Distribution, Abundance, and Behavior of Sharks and Rays. In Shark Research: Emerging Technologies and Applications for the Field and Laboratory; Carrier, J.C., Heithaus, M.R., Simpfendorfer, C.A., Eds.; CRC Press: Boca Raton, FL, USA, 2018; pp. 71-83. [CrossRef]

18. Lowe, C.G.; White, C.F.; Clark, C.M. Use of Autonomous Vehicles for Tracking and Surveying of Acoustically Tagged Elasmobranchs. In Shark Research: Emerging Technologies and Applications for the Field and Laboratory; Carrier, J.C., Heithaus, M.R., Simpfendorfer, C.A., Eds.; CRC Press: Boca Raton, FL, USA, 2018; pp. $93-111$. [CrossRef] 
19. Koski, W.R.; Allen, T.; Ireland, D.; Buck, G.; Smith, P.R.; Macrander, A.M.; Halick, M.A.; Rushing, C.; Sliwa, D.J.; McDonald, T.L. Evaluation of an unmanned airborne system for monitoring marine mammals. Aquat. Mamm. 2009, 35, 347. [CrossRef]

20. Gough, W.T.; Segre, P.S.; Bierlich, K.; Cade, D.E.; Potvin, J.; Fish, F.E.; Dale, J.; di Clemente, J.; Friedlaender, A.S.; Johnston, D.W.; et al. Scaling of swimming performance in baleen whales. J. Exp. Biol. 2019, 222. [CrossRef]

21. Gray, P.C.; Fleishman, A.B.; Klein, D.J.; McKown, M.W.; Bézy, V.S.; Lohmann, K.J.; Johnston, D.W. A convolutional neural network for detecting sea turtles in drone imagery. Methods Ecol. Evol. 2019, 10, 345-355. [CrossRef]

22. Arranz, P.; Benoit-Bird, K.J.; Friedlaender, A.S.; Hazen, E.L.; Goldbogen, J.A.; Stimpert, A.K.; DeRuiter, S.L.; Calambokidis, J.; Southall, B.L.; Fahlman, A.; et al. Diving Behavior and Fine-Scale Kinematics of Free-Ranging Risso's Dolphins Foraging in Shallow and Deep-Water Habitats. Front. Ecol. Evol. 2019, 7, 53. [CrossRef]

23. Durban, J.W.; Fearnbach, H.; Barrett-Lennard, L.; Perryman, W.; Leroi, D. Photogrammetry of killer whales using a small hexacopter launched at sea. J. Unmanned Veh. Syst. 2015, 3, 131-135. [CrossRef]

24. Raoult, V.; Tosetto, L.; Williamson, J.E. Drone-based high-resolution tracking of aquatic vertebrates. Drones 2018, 2, 37. [CrossRef]

25. Raoult, V.; Williamson, J.E.; Smith, T.M.; Gaston, T.F. Effects of on-deck holding conditions and air exposure on post-release behaviours of sharks revealed by a remote operated vehicle. J. Exp. Mar. Biol. Ecol. 2019, 511, 10-18. [CrossRef]

26. Raoult, V.; Tosetto, L.; Harvey, C.; Nelson, T.M.; Reed, J.; Parikh, A.; Chan, A.J.; Smith, T.M.; Williamson, J.E. Remotely operated vehicles as alternatives to snorkellers for video-based marine research. J. Exp. Mar. Biol. Ecol. 2020, 522, 151253. [CrossRef]

27. Bevan, E.; Whiting, S.; Tucker, T.; Guinea, M.; Raith, A.; Douglas, R. Measuring behavioral responses of sea turtles, saltwater crocodiles, and crested terns to drone disturbance to define ethical operating thresholds. PLoS ONE 2018, 13, e0194460. [CrossRef] [PubMed]

28. Raoult, V.; Colefax, A.P.; Allan, B.M.; Cagnazzi, D.; Castelblanco-Martínez, N.; Ierodiaconou, D.; Johnston, D.W.; Landeo-Yauri, S.; Lyons, M.; Pirotta, V.; et al. Operational Protocols for the Use of Drones in Marine Animal Research. Drones 2020, 4, 64. [CrossRef]

29. Skomal, G.B.; Hoyos-Padilla, E.M.; Kukulya, A.; Stokey, R. Subsurface observations of white shark Carcharodon carcharias predatory behaviour using an autonomous underwater vehicle. J. Fish Biol. 2015, 87, 1293-1312. [CrossRef] [PubMed]

30. Clark, C.M.; Forney, C.; Manii, E.; Shinzaki, D.; Gage, C.; Farris, M.; Lowe, C.G.; Moline, M. Tracking and Following a Tagged Leopard Shark with an Autonomous Underwater Vehicle. J. Field Robot. 2013, 30, 309-322. [CrossRef]

31. Forney, C.; Manii, E.; Farris, M.; Moline, M.A.; Lowe, C.G.; Clark, C.M. Tracking of a tagged leopard shark with an AUV: Sensor calibration and state estimation. In Proceedings of the 2012 IEEE International Conference on Robotics and Automation, Saint Paul, MN, USA, 14-18 May 2012; pp. 5315-5321. [CrossRef]

32. Nathan, R.; Getz, W.M.; Revilla, E.; Holyoak, M.; Kadmon, R.; Saltz, D.; Smouse, P.E. A movement ecology paradigm for unifying organismal movement research. Proc. Natl. Acad. Sci. USA 2008, 105, 19052-19059. [CrossRef]

33. Doan, M.D.; Kajiura, S.M. Adult blacktip sharks (Carcharhinus limbatus) use shallow water as a refuge from great hammerheads (Sphyrna mokarran). J. Fish Biol. 2020, 96, 1530-1533. [CrossRef]

34. Colefax, A.P.; Kelaher, B.P.; Pagendam, D.E.; Butcher, P.A. Assessing White Shark (Carcharodon carcharias) Behavior Along Coastal Beaches for Conservation-Focused Shark Mitigation. Front. Mar. Sci. 2020, 7, 268. [CrossRef]

35. Kiszka, J.J.; Mourier, J.; Gastrich, K.; Heithaus, M.R. Using unmanned aerial vehicles (UAVs) to investigate shark and ray densities in a shallow coral lagoon. Mar. Ecol. Prog. Ser. 2016, 560, 237-242. [CrossRef]

36. Gore, M.; Abels, L.; Wasik, S.; Saddler, L.; Ormond, R. Are close-following and breaching behaviours by basking sharks at aggregation sites related to courtship? J. Mar. Biol. Assoc. UK 2019, 99, 681-693. [CrossRef]

37. Rieucau, G.; Kiszka, J.J.; Castillo, J.C.; Mourier, J.; Boswell, K.M.; Heithaus, M.R. Using unmanned aerial vehicle (UAV) surveys and image analysis in the study of large surface-associated marine species: A case study on reef sharks Carcharhinus melanopterus shoaling behaviour. J. Fish Biol. 2018, 93, 119-127. [CrossRef] 
38. Whitney, N.M.; Lear, O.; Gleiss, A.C.; Payne, N.; White, C.F. Advances in the Application of High-Resolution Biologgers to Elasmo-Branch Fishes. In Shark Research: Emerging Technologies and Applications for the Field and Laboratory; Carrier, J.C., Heithaus, M.R., Simpfendorfer, C.A., Eds.; CRC Press: Boca Raton, FL, USA, 2018; pp. 45-70. [CrossRef]

39. Papastamatiou, Y.P.; Meyer, C.G.; Watanabe, Y.Y.; Heithaus, M.R. Animal-Borne Video Cameras and Their Use to Study Shark Ecology and Conservation. In Shark Research: Emerging Technologies and Applications for the Field and Laboratory; Carrier, J.C., Heithaus, M.R., Simpfendorfer, C.A., Eds.; CRC Press: Boca Raton, FL, USA, 2018; pp. 83-92. [CrossRef]

40. Kajiura, S.M.; Tellman, S.L. Quantification of Massive Seasonal Aggregations of Blacktip Sharks (Carcharhinus limbatus) in Southeast Florida. PLoS ONE 2016, 11, 911. [CrossRef] [PubMed]

41. Joyce, K.; Duce, S.; Leahy, S.; Leon, J.; Maier, S. Principles and practice of acquiring drone-based image data in marine environments. Mar. Freshw. Res. 2018, 70. [CrossRef]

42. Rohr, J.J.; Fish, F.E. Strouhal numbers and optimization of swimming by odontocete cetaceans. J. Exp. Biol. 2004, 207, 1633-1642. [CrossRef] [PubMed]

43. McComb, D.M.; Tricas, T.C.; Kajiura, S.M. Enhanced visual fields in hammerhead sharks. J. Exp. Biol. 2009, 212, 4010-4018. [CrossRef]

44. Lowe, C.G.; Holland, K.N.; Wolcott, T.G. A new acoustic tailbeat transmitter for fishes. Fish. Res. 1998, 36, 275-283. [CrossRef]

45. Brown, D.D.; Kays, R.; Wikelski, M.; Wilson, R.; Klimley, A.P. Observing the unwatchable through acceleration logging of animal behavior. Anim. Biotelemetry 2013, 1, 1-16. [CrossRef]

46. Saadat, M.; Fish, F.E.; Domel, A.G.; Di Santo, V.; Lauder, G.V.; Haj-Hariri, H. On the rules for aquatic locomotion. Phys. Rev. Fluids 2017, 2, 083102. [CrossRef]

47. Taylor, G.K.; Nudds, R.L.; Thomas, A.L.R. Flying and swimming animals cruise at a Strouhal number tuned for high power efficiency. Nature 2003, 425, 707-711. [CrossRef] [PubMed]

48. Triantafyllou, M.S.; Triantafyllou, G.S.; Gopalkrishnan, R. Wake mechanics for thrust generation in oscillating foils. Phys. Fluids Fluid Dyn. 1991, 3, 2835-2837. [CrossRef]

49. Triantafyllou, G.S.; Triantafyllou, M.S.; Grosenbaugh, M.A. Optimal Thrust Development in Oscillating Foils with Application to Fish Propulsion. J. Fluids Struct. 1993, 7, 205-224. [CrossRef]

50. Triantafyllou, M.S.; Triantafyllou, G.S.; Yue, D.K.P. Hydrodynamics of Fishlike Swimming. Annu. Rev. Fluid Mech. 2000, 32, 33-53. [CrossRef]

51. Eloy, C. Optimal Strouhal number for swimming animals. J. Fluids Struct. 2012, 30, 205-218. [CrossRef]

52. Floryan, D.; Van Buren, T.; Smits, A.J. Efficient cruising for swimming and flying animals is dictated by fluid drag. Proc. Natl. Acad. Sci. USA 2018, 115, 8116. [CrossRef]

53. Fish, F.; Shannahan, L. The role of the pectoral fins in body trim of sharks. J. Fish Biol. 2000, 56, 1062-1073. [CrossRef]

54. Webb, P.W.; Keyes, R.S. Swimming kinematics of sharks. Fish. Bull. 1982, 80, 803-812.

55. Fish, F.E.; Kolpas, A.; Crossett, A.; Dudas, M.A.; Moored, K.W.; Bart-Smith, H. Kinematics of swimming of the manta ray: Three-Dimensional analysis of open-water maneuverability. J. Exp. Biol. 2018, 221. [CrossRef]

56. Watanabe, Y.Y.; Lydersen, C.; Fisk, A.T.; Kovacs, K.M. The slowest fish: Swim speed and tail-beat frequency of Greenland sharks. J. Exp. Mar. Biol. Ecol. 2012, 426-427, 5-11. [CrossRef]

57. Lowe, C.G. Bioenergetics of free-ranging juvenile scalloped hammerhead sharks (Sphyrna lewini) in Kāne'ohe Bay, Ō'ahu, HI. J. Exp. Mar. Biol. Ecol. 2002, 278, 141-156. [CrossRef]

58. Lauder, G.V.; Di Santo, V. 6-Swimming Mechanics and Energetics of Elasmobranch Fishes. In Fish Physiology; Shadwick, R.E., Farrell, A.P., Brauner, C.J., Eds.; Academic Press: New York, NY, USA, 2015; Volume 34A, pp. 219-253.

59. Hoffmann, S.L.; Buser, T.J.; Porter, M.E. Comparative morphology of shark pectoral fins. J. Morphol. 2020, 281, 1501-1516. [CrossRef] [PubMed]

60. Crofts, S.B.; Shehata, R.; Flammang, B.E. Flexibility of Heterocercal Tails: What Can the Functional Morphology of Shark Tails Tell Us about Ichthyosaur Swimming? Integr. Org. Biol. 2019, 1, obz002. [CrossRef]

61. Maia, A.; Lauder, G.V.; Wilga, C.D. Hydrodynamic function of dorsal fins in spiny dogfish and bamboo sharks during steady swimming. J. Exp. Biol. 2017, 220, 3967-3975. [CrossRef] [PubMed] 
62. Hoffmann, S.L.; Porter, M.E. Body and Pectoral Fin Kinematics During Routine Yaw Turning in Bonnethead Sharks (Sphyrna tiburo). Integr. Org. Biol. 2019, 1, obz014. [CrossRef]

63. Flammang, B.E.; Lauder, G.V.; Troolin, D.R.; Strand, T.E. Volumetric imaging of fish locomotion. Biol. Lett. 2011, 7, 695-698. [CrossRef]

64. Porter, M.E.; Ewoldt, R.H.; Long, J.H. Automatic control: The vertebral column of dogfish sharks behaves as a continuously variable transmission with smoothly shifting functions. J. Exp. Biol. 2016, 219, 2908-2919. [CrossRef]

65. Porter, M.E.; Roque, C.M.; Long, J.H., Jr. Swimming fundamentals: Turning performance of leopard sharks (Triakis semifasciata) is predicted by body shape and postural reconfiguration. Zoology 2011, 114, 348-359. [CrossRef]

66. Long, J.H.; Nipper, K.S. The Importance of Body Stiffness in Undulatory Propulsion. Integr. Comp. Biol. 1996, 36, 678-694. [CrossRef]

67. Hays, G.C.; Ferreira, L.C.; Sequeira, A.M.M.; Meekan, M.G.; Duarte, C.M.; Bailey, H.; Bailleul, F.; Bowen, W.D.; Caley, M.J.; Costa, D.P.; et al. Key questions in marine megafauna movement ecology. Trends Ecol. Evol. 2016, 31, 463-475. [CrossRef]

Publisher's Note: MDPI stays neutral with regard to jurisdictional claims in published maps and institutional affiliations.

(C) 2020 by the authors. Licensee MDPI, Basel, Switzerland. This article is an open access article distributed under the terms and conditions of the Creative Commons Attribution (CC BY) license (http://creativecommons.org/licenses/by/4.0/). 